\title{
Identifying and prioritizing factors affecting the security of sport facilities (Case of Iran)
}

\author{
Identificación y priorización de factores que afectan la seguridad de las instalaciones \\ deportivas (caso de Irán)
}

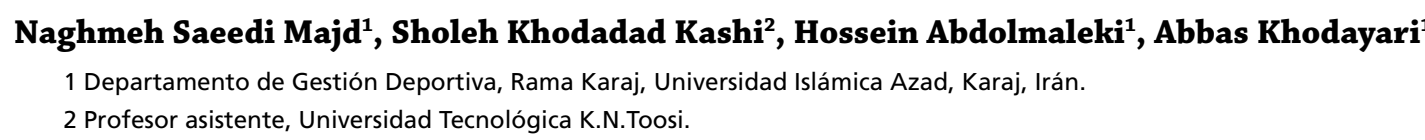

CORRESPONDENCIA:

Hossein Abdolmaleki

h.abdolmaleki@kiau.ac.ir

Recepción: abril 2020 • Aceptación: febrero 2021
CÓMO CITAR EL ARTÍCULO:

Saeidi Majd, N., Khodadad Kashi, S., Abdolmaleki, H., \& Khodatari, A. (2021). Identifying and prioritizing factors affecting the security of sport facilities (Case of Iran). Cultura, Ciencia y Deporte, 16(50), 593-603. http://dx.doi.org/ 10.12800/ccd.v16i50.1433

\section{Abstract}

The purpose of this study is to identify and prioritize the factors affecting the security of Iranian sports complexes. The mixed research method is a combination of qualitative and quantitative methods. The statistical population of this study consists of two parts: qualitative and quantitative. In the qualitative section, sports management experts have comprised 11 Delphi panel members. In the quantitative section, the statistical population of this study is managers and staff of Karaj sports complexes $(\mathrm{N}=785)$. In the qualitative section, all 11 Delphi Panel Experts have been selected as the sample. In the quantitative section 121 questionnaires have been returned to the researcher. The results of this study show that physical protection systems are the most important factor in securing sports complexes, followed by security personnel, sports facility structure, qualification and accreditation, entrance control, emergency management, environmental control, Education, risk management, communication, protection against toxic substances and cultural practices. In this study, the effective factors in the security of sport venues in Iran were obtained. Therefore, in order to improve the level of security of sport events, managers are suggested to consider the factors obtained in this study.

Key words: Security, sport facilities, fuzzy Delphi, MADM.

\section{Resumen}

El propósito de este estudio es identificar y priorizar los factores que afectan la seguridad de los complejos deportivos iraníes. El método de investigación mixto es una combinación de métodos cualitativos y cuantitativos. La población estadística de este estudio consta de dos partes: cualitativa y cuantitativa. En el apartado cualitativo, los expertos en gestión deportiva han formado a 11 miembros del panel Delphi. En la sección cuantitativa, la población estadística de este estudio son los gerentes y el personal de los complejos deportivos de Karaj $(\mathrm{N}=785)$. En la sección cualitativa, los 11 expertos del panel Delphi han sido seleccionados como muestra. En la sección cuantitativa se han devuelto al investigador 121 cuestionarios. Los resultados de este estudio muestran que los sistemas de protección física son el factor más importante en la seguridad de los complejos deportivos, seguido del personal de seguridad, estructura de la instalación deportiva, calificación y acreditación, control de ingreso, gestión de emergencias, control ambiental, educación, gestión de riesgos, comunicación, protección. contra sustancias tóxicas y prácticas culturales. En este estudio, se obtuvieron los factores efectivos en la seguridad de las instalaciones deportivas en Irán. Por tanto, para mejorar el nivel de seguridad de los eventos deportivos, se sugiere a los gestores que consideren los factores obtenidos en este estudio.

Palabras clave: Seguridad, instalaciones deportivas, fuzzy Delphi, MADM. 


\section{Introduction}

Sociologists believe that sport is a social and cultural phenomenon that is inextricably linked to social institutions and structures. Social phenomena can be influenced by risk factors for various reasons and cause problems for society (Espinal-Ruiz, MedinaVásquez, \& Da Cunha-Bastos, 2019; Martos-Garcia, Devís-Devís, \& Sparkes, 2009; Pradisathaporn, Kaviya, Fujii, \& Yupapin, 2011). Sport and sporting events can also be affected by these problems and risks due to their social nature and ultimately cause a crisis for society (Khabiri, Sajadi, Doosti, \& Mohamadian, 2010; Shah Mansouri \& Mozafari, 2006).

Security means not worrying, being free from harm, danger, threats and reassurance, peace and comfort (Cunningham III, 2007; del Campo \& Sánchez, 2016; Giulianotti \& Klauser, 2010, 2011; Hall, 2006). From a social and cultural point of view, security can be regarded as a state of peace in which people are assured of their lives, property, honor, dignity, identity, communication, thoughts and values in the present and future, and can be endured day and night by taking the least risk possible (Baena-González, García-Tascón, Chavarría-Ortíz, Martínez-Martín, \& Gallardo, 2020; García-Tascón, Guerrero, Luengo, Martínez-López, \& González, 2014; Gordon, Czekanski, \& DeMeo, 2016; Hall, 2010; Hall, Cieslak, Cooper, \& McGee, 2010; Khabiri et al., 2010; Maciá, Gallardo, Sánchez, \& García-Tascón, 2020; Martos-Garcia et al., 2009). According to Maslow (1942), security is as follows: The security feelings are a syndrome. That is, the name "security" is a generalized label for many more specific feelings which overlap and intertwine, and which are all functions of one another. Because of this common character, we may group them together and consider them in their "wholeness," in their unitary rather than in their diverse qualities. The word "security" or "insecurity" is in-tended as a label for this peculiar aspect of "wholeness" that may be discerned in the multiplicity of particular symptoms with which we shall deal (Maslow, 1942). So, Security is one of the most important human needs that has been addressed in many theories and research in psychology, sociology, political science, and management, and no doubt, no element more important to the development and the development of society as well as the development of talent. Security and peace are not for society (Delavar, 2008). Also, the Islamic Republic of Iran, according to the Constitution, is a system based on the belief in "the dignity and high value of human and his/her freedom" (paragraph 6 of Article 2) and "human happiness in the whole of human society as its ideal and independence and freedom and government He recognizes right and justice as the right of all the people of the world" (Article 154) (Poursaeed, 2008).

Security has many areas such as social, political, cultural, Economic and food security and so on. Another area of security is sport security, which means that sporting events and competitions are free of any danger or threat. Sport security management studies the nature and scope of sport security and issues threatening sporting events such as terrorism (motivation for terrorist activities, modes of terrorist activity and the effects of terrorist activity), natural disasters, and crowding issues in sport (Hall, Ward, Cunningham, \& Marciani, 2008).

According to reports, about several million people exercise at sport venues around the world each year or go to sport venues to watch sports events. Such a population is a natural target for terrorism and other crimes because of the number of people in a small area (Alidostghahfarrokhi \& Ahmadi, 2012; Delgado \& Gómez, 2018). The overcrowded stadium crowd, the potential for high mortality rates in the attacks as a deadly tool, attracts the attention of terrorists (Delavar, 2008; Taylor \& Toohey, 2005). Organizers of sporting events around the world spend more than \$2 million each year on security activities (Zarei, 2019). Security costs associated with safeguards include human resources and physical support systems, environmental control, access control, risk and crisis management, population management, traffic management, and access, and traffic and parking management (Harati, 2019; Taylor \& Toohey, 2005, 2011; Voorhees, 2018). Research shows that most of our sport venues and venues are not yet properly protected. The quantitative and qualitative status of sport venues and events can vary depending on the structure of the sport venues, capacity, type of event, and the number of resources available (Naderiyan, Poorsoltanzarandi, \& Rohani, 2013). Observing the security aspects of designing, constructing and operating sport venues and venues, as well as ensuring the safety of athletes, spectators, and fans of sports teams during sporting events has long been a concern for sporting and event managers (Majidi, Kashef, Ahadi, \& Rasoolazar, 2016).

Certainly, improving and upgrading the security system of events and sport venues will result in minimal risk competitions. Reducing the risk of sporting events will increase the attendance of spectators in sport venues, the chance to host international events, as well as increasing the exposure of foreign teams to attend a variety of domestic tournaments. Security incidents in Iranian sport venues will question the image of the country in international forums; Improving the 
security of stadiums by conducting such scientific studies and providing a platform for other studies in the field, while preventing accidents in sport venues and protecting the lives of those present (spectators, athletes, coaches, etc.), as well as preventing damage to the country's sports infrastructure, it will demonstrate stability and security within the country and provide a positive image throughout the world (Hematinezhad, Taylor, Gholizadeh, \& Faraji, 2016; Hemmatinezhad, Gholizadeh, Taylor, \& Faraji, 2016).

\section{Theoretical Framework and Research Question}

Harati et al. (1977) conducted a study to investigate the physical security dimensions affecting the security of volleyball stadiums in Iran. Research findings showed that physical security is one of the main factors affecting the security of volleyball stadiums in Iran. Toxic and chemical control (0.91), internal control (0.90), environmental control (0.70) and playground entry control (0.59) were considered as the most important physical security factors in volleyball stadium security (Harati, 2019). ( $\mathrm{P}<0.05)$. On the other hand, Kargar et al. (2017) have conducted research to present a model of factors affecting the security of sporting events in Iran. According to the research findings, the factors affecting the security of sporting events can be divided into five domains: infrastructure, technology, media and advertising, human resources and cultural practices. The results also showed that the process of police security management of sporting events includes the steps of tournament management and planning, policies, stadium management system, estimates, traffic control, and interagency interactions and partnerships. At the end of the research, the process model of the factors influencing the security of sporting events, security management steps and its consequences are mentioned (Kargar, Ghafouri, Mohammadi Moghaddam, \& Moradi Siasar, 2017). Hematinejad et al. (2016) have conducted a study identifying the main factors affecting the security of Iranian football stadiums and prioritizing them using a hierarchical analysis method. Four factors were identified as the most important factors affecting stadium security: infrastructure, physical protection of the stadium, race planning, and management, as well as personnel and staff (Hematinezhad et al., 2016). Also, Menaker et al. (2019) have conducted a study of mass pattern changes in the vicinity of Cleveland's sporting venues on race day. Confirmed results showed that sports events in each of these locations influenced the frequency, type and timing of crime occurrence in the vicinity of these areas and the frequency of crime was greater on game days. Besides, the contests have had the greatest impact on increasing the frequency of violent crimes, resisting arrest, and crime reports (Menaker, McGranahan, \& Sheptak Jr, 2019). Voorhees (2018), research on risk reduction: a Delphi study to identify the competencies for managing the security of sporting events. The results of the study classified 136 core competencies into seven categories: risk management, emergency planning, problem-solving and decision making, leadership, communication, collaborative relationships, and human resource management. According to the results of this study, sports security management and sporting event management professionals and industry stakeholders can use a valid list of competencies to develop human capital and improve the performance of the strategic Human Resource Management (HRM) program (Voorhees, 2018).

In general, studies of the security of sporting events and venues are very limited, and most studies have been carried out abroad at major sporting events such as the Olympics and World Cup matches, and at lowerlevel sporting events as well as general principles. There has been little research on the construction of sport facilities.

Bearing in mind the importance of safety in society and especially in sporting environments, there is a great need for scientific research to assess the security of sport facilities in the country and especially during events to prevent accidents and improve the current situation. So, the main question of the present study is only what are the factors affecting the security of sport facilities?

\section{Method}

The current study involved two phases. In the first phase, we developed an initial set of factors affecting sport security and refined this list through applying Fuzzy Delphi techniques with a panel of experts. This phase allowed us to identify the most important factors affecting sport security in Iran. In the second phase, we collected data from managers and staff of Karaj sport complexes, evaluated the relative importance of each factor according to five decision criteria, and used a MADM model to combine relative rankings into a single ordered importance list. We review the methods associated with each phase in the following sections.

\section{Phase 1: Fuzzy Delphi Technique}

The Delphi method (Dalkey, Brown, \& Cochran, 1970) is a research method that seeks to establish consensus 
on a complex problem amongst a group of experts in a particular field. Experts' opinions are converged, typically via several rounds of questionnaires (Okoli \& Pawlowski, 2004). The approach is well-established in studying sport organizations e.g., (Abdolmaleki, Mirzazadeh, \& Ghahfarokhhi, 2018; Anderson et al., 2019; Costa, 2005). The Delphi method is an effective process of establishing consensus expert opinions in a given field. However, the method does have weaknesses including: 1) multiple survey cycles are time consuming for both participants and researchers; 2) multiple surveys are expensive to administer and analyze; 3) repeated expert cooperation is required before consensus emerges, needlessly increasing the difficulty of coordination and communication; 4) lack of complete consensus amongst experts makes it easy to misinterpret the collective position, especially for complex contexts; 5) the analytical process can weaken or exclude minority opinions (Hsu \& Yang, 2000; Ishikawa et al., 1993).

To overcome these limitations, Murray et al. (1985) proposed integrating fuzzy set theory (Abdolmaleki et al., 2018) with the Delphi method. Fuzzy set theory enables representation of the uncertainty and imprecision in real world systems. The key underlying principle of fuzzy set theory is that while some sets have sharply-defined inclusion criteria, that is not the case in many applications and it can be useful to consider set membership along a continuum from totally not a member to totally a member (Chen \& Klein, 1997). Thus, fuzzy theory has capacity to represent vague or imprecise data, directly incorporating a measure of uncertainty (Kashtidar, Gholizadeh, Okhravi, \& Abdolmaleki, 2017; Nobakht, Ehsani, Koozehchian, \& Amiri, 2015). Applied to the Delphi method, membership degree establishes the membership function of each expert's perspective on each study element. Further refining the Fuzzy Delphi method, Ishikawa et al. (1993) introduced the max-min algorithm and fuzzy integration, which allow compilation of expert opinions into fuzzy numbers.

Consistent with previous fuzzy Delphi studies, we deployed four-step approach to data analyses. First, a list of 16 factors affecting the security of sport facilities were identified from the academic literature and five sport security experts evaluated each through semistructured interviews. Interview questions prompted experts to evaluate whether they recognized each factor on the list. 14 factors were retained. Second, we surveyed 11 practitioners to determine the final version of the list. Third, expert opinions were organized into estimates and triangular fuzzy numbers were established. Finally, as part of the defuzzification process, the Mamdani Fuzzy Inference System (Poursaeed, 2008) converted the fuzzy outputs into crisp output values. We used the Centroid method, one of the most popular defuzzification techniques to transform the fuzzy values into crisp values (Hussler, Muller, \& Rondé, 2011).

\section{Data collection}

For phase 1, Arguably the most important decision within a Delphi study is the selection of panelists. Diverse participants are generally preferable (Costa, 2005). 11 sport security practitioners accepted our invitation. 8 people were men and other were women. They had at least 5 years' experience in sport security management teaching or/and research. 3 were full Professor, 5 were associate professor and 3 were assistant professor. This number was consistent with the widely accepted size of 10-20 participants for a Delphi panel (Dalkey et al., 1970).

In fuzzy Delphi, the $D(A)^{\sim}$ criterion and 0.7 thresholds were used to select key indicators:

$$
\begin{gathered}
A^{\sim}=\left(L_{A}, M_{A}, U_{A}\right) \\
L_{A}=\min \left(X_{A i}\right) ; U_{A}=\max \left(X_{A i}\right) ; M_{A}=\sqrt[n]{X_{A 1} \times X_{A 2} \times \ldots \times X_{A n}} \\
D(A)^{\sim}=\frac{\left(L_{A}+\left(4 \times M_{A}\right)+U_{A}\right.}{6} A^{\sim}=\left(L_{A}, M_{A}, U_{A}\right) \\
L_{A}=\min \left(X_{A i}\right) ; U_{A}=\max \left(X_{A i}\right) ; M_{A}=\sqrt[n]{X_{A 1} \times X_{A 2} \times \ldots \times X_{A n}} \\
D(A)^{\sim}=\frac{\left(L_{A}+\left(4 \times M_{A}\right)+U_{A}\right.}{6} \\
\text { If } \geq 0.7 \text { the index is selected } \\
\text { If }<0.7 \text { the index is deleted (Abdolmaleki et al., 2018). }
\end{gathered}
$$

\section{Phase 2: Multiple Attribute Decision Making Model}

In the second phase, we surveyed managers and staff of Karaj sport complexes to better understand what aspects of sport security they found most important. We used a multiple attribute decision making (MADM) model to rank the factors affecting sport security. MADM models are widely used in complex decision making, where multiple, potentially contradictory, criteria are necessary (Zavadskas, Turskis, \& Kildiené, 2014; Zhang, 2004). The power of these techniques lies in reducing the complexity of decision-making and providing a structured framework to decision-making, leading to adoption by decision makers across fields (Chen \& Klein, 1997; Li, 2010).

\section{Data Collection}

For phase 2, the statistical population includes managers and staff of Karaj sport complexes ( $\mathrm{N}=$ 785). Based on PASS statistical software and research objectives, the sample size was estimated between 
83 to 156 people. We distributed 150 questionnaires among the sample. After collecting the questionnaires and discarding those that were distorted and unusable, 121 questionnaires remained and were used in the analysis.

\section{Results}

The results for quantitative sample age group are 40.33 years old although they are also older (59 years) and younger (28years). 70 people were men and 51 were women. Fuzzy Delphi method has been used to identify the factors of sport site safety questionnaire based on the following factors: environmental control, entrance control, qualification and accreditation of individuals, physical protection systems, risk management, emergency management, communications, Security personnel, training (modeling and simulation), protection against toxic substances, sports facility structure and cultural practices were identified.

Table 1. Results of the fuzzy Delphi method.

\begin{tabular}{cll}
\hline Row & Indicator Criterion & $D(A) \sim$ \\
\hline $\mathbf{1}$ & Environmental control & 0.703 \\
\hline $\mathbf{2}$ & Entrance control & 0.852 \\
\hline $\mathbf{3}$ & $\begin{array}{l}\text { Examine the qualifications and credentials } \\
\text { of individuals }\end{array}$ & 0.760 \\
\hline $\mathbf{4}$ & Physical protection systems & 0.813 \\
\hline $\mathbf{5}$ & Risk management & 0.789 \\
\hline $\mathbf{6}$ & Emergency Communications Management & 0.734 \\
\hline $\mathbf{7}$ & connections & 0.766 \\
\hline $\mathbf{8}$ & Security personnel & 0.808 \\
\hline $\mathbf{9}$ & Training (modeling and simulation) & 0.723 \\
\hline $\mathbf{1 0}$ & Protection against toxic substances & 0.733 \\
\hline $\mathbf{1 1}$ & The structure of the sport venue & 0.741 \\
\hline $\mathbf{1 2}$ & Cultural practices & 0.706 \\
\hline $\mathbf{1 3}$ & Geographical location of the sport venue & 0.592 \\
\hline $\mathbf{1 4}$ & Research and Development & 0.630 \\
\hline
\end{tabular}

Multi Attribute decision-making models (MADM) have been used to rank the factors affecting the security of sports complexes. Multidisciplinary decisionmaking techniques are one of the most popular models of decision making in the last two decades. These techniques and models have been commonly used in complex decision making (when multiple criteria are sometimes met). These techniques and models have been widely used in complex decision making (when multiple criteria are sometimes met). The high power of these techniques in reducing the complexity of decision making, the simultaneous use of quantitative and qualitative criteria, granting them a structured framework for decision-making and, ultimately, their ease of use has made them useful tools for decisionmakers in different disciplines. These techniques formulate decision problems in a matrix (as in the following matrix) and perform the necessary analysis on them.

\begin{tabular}{ccccc}
\hline Index / Options & $\mathbf{X 1}$ & $\mathbf{X 2}$ & $\ldots$ & $\mathbf{X n}$ \\
\hline A1 & $r 11$ & $r 12$ & $\ldots$ & $r 1 n$ \\
\hline A2 & $r 21$ & $r 22$ & $\ldots$ & $r 2 n$ \\
\hline$\ldots$ & & & $\ldots$ & \\
\hline Am & $r m 1$ & $r m 2$ & $\ldots$ & $r m n$ \\
\hline
\end{tabular}

In this matrix, Ai represents option $\mathrm{i}, \mathrm{Xj}$ represents index $j$, and Rij represents index value $j$ for option $i$.

Due to a large number of multiple-attribute decisionmaking techniques, five useful techniques which have been used in this field, namely "Linear Assignment techniques, Elimination et Choice Translating Reality (ElECTRE), Simple Additive Weighted (SAW), Technique for the Order Preference by Similarity to Ideal Solution (TOPSIS), and Linear Programming for Multidimensional Analysis of Preferences (LINMAP)", have been used in this study. A decision matrix has been also formed after data collection, which consisted of 12 rows (number of factors) and 121 columns (number of Participants). It is worth noting that before performing the computational steps of the linear allocation techniques, ElECTRE, SAW, TOPSIS and LINMAP, the coefficients of the importance of the indices must first be determined. In this study, these coefficients have been generated using the Shannon entropy method. Following the above techniques, the following results are shown in Table 2.

In the decision-making techniques used in this study, different ratings have been obtained for a given factor, according to the different characteristics of each method. To reach consensus in different rankings, different integration methods can be utilized. In this research, the Copeland integration method has been used. This method specifies the number of wins and losses for each criterion. For example, if we look at the data in Table 2, there are four methods (Linear Assignment, SAW, and TOPSIS) that prefer 4 to 8. Similarly, as can be perceived, the two methods (ElECTRE and LINMAP) prefer the criterion of 8 over 4. The number of methods that prefer criterion 4 to criterion 8 is greater than the number of methods that prefers criterion 8 to criterion 4 . Therefore, criterion 4 is more preferred than criterion 8 , and this is shown with $\mathrm{M}$ in pairwise comparison. If there is no majority 
Table 2. Ranking of factors affecting the security of sport complexes based on different multi-Attribute decision-making techniques.

\begin{tabular}{|c|c|c|c|c|c|c|c|c|}
\hline Component & Linear Assignment & ELECTRE & SAW & & TOPSIS & & LINMA & \\
\hline & & & Rank & WI & Rank & $\mathrm{Cl}$ & Rank & TI \\
\hline 1 & 7 & 7 & 6 & 0.915 & 7 & 0.744 & 7 & -0.00920 \\
\hline 2 & 6 & 5 & 5 & 0.917 & 4 & 0.812 & 5 & -0.00932 \\
\hline 3 & 3 & 4 & 4 & 0.919 & 5 & 0.801 & 4 & -0.00935 \\
\hline 4 & 1 & 2 & 1 & 0.931 & 1 & 0.848 & 3 & -0.00938 \\
\hline 5 & 9 & 9 & 10 & 0.826 & 11 & 0.686 & 9 & -0.00908 \\
\hline 6 & 5 & 6 & 7 & 0.903 & 6 & 0.778 & 6 & -0.00923 \\
\hline 7 & 10 & 10 & 9 & 0.841 & 8 & 0.714 & 10 & -0.00900 \\
\hline 8 & 2 & 1 & 2 & 0.927 & 2 & 0.839 & 2 & -0.00940 \\
\hline 9 & 8 & 8 & 8 & 0.897 & 9 & 0.701 & 8 & -0.00917 \\
\hline 10 & 11 & 12 & 11 & 0.810 & 10 & 0.698 & 11 & -0.00900 \\
\hline 11 & 4 & 3 & 3 & 0.920 & 3 & 0.826 & 1 & -0.00942 \\
\hline 12 & 12 & 11 & 12 & 0.788 & 12 & 0.665 & 12 & -0.00878 \\
\hline
\end{tabular}

Table 3. Results of pairwise comparisons between factors.

\begin{tabular}{|c|c|c|c|c|c|c|c|c|c|c|c|c|c|}
\hline Criterion & 1 & 2 & 3 & 4 & 5 & 6 & 7 & 8 & 9 & 10 & 11 & 12 & Number of wins \\
\hline 1 & - & $x$ & $x$ & $x$ & M & $x$ & $M$ & $x$ & $M$ & $M$ & $x$ & $M$ & 5 \\
\hline 2 & M & - & $\mathrm{x}$ & $x$ & M & $M$ & $\mathrm{M}$ & $x$ & $\mathrm{M}$ & $\mathrm{M}$ & $x$ & $\mathrm{M}$ & 7 \\
\hline 3 & $\mathrm{M}$ & $\mathrm{M}$ & - & $x$ & M & M & $\mathrm{M}$ & $\mathrm{x}$ & $\mathrm{M}$ & $\mathrm{M}$ & $x$ & $\mathrm{M}$ & 8 \\
\hline 4 & $\mathrm{M}$ & $\mathrm{M}$ & M & - & M & M & $\mathrm{M}$ & $\mathrm{M}$ & $\mathrm{M}$ & $\mathrm{M}$ & $\mathrm{M}$ & $\mathrm{M}$ & 11 \\
\hline 5 & $\mathrm{x}$ & $\mathrm{x}$ & $\mathrm{x}$ & $\mathrm{X}$ & - & $x$ & $\mathrm{M}$ & $\mathrm{X}$ & $\mathrm{x}$ & $\mathrm{M}$ & $x$ & $\mathrm{M}$ & 3 \\
\hline 6 & M & $\mathrm{x}$ & $x$ & $\mathrm{X}$ & M & - & $\mathrm{M}$ & $x$ & $\mathrm{M}$ & $\mathrm{M}$ & $x$ & $\mathrm{M}$ & 6 \\
\hline 7 & $X$ & $X$ & $X$ & $X$ & $x$ & $x$ & - & $X$ & $x$ & $\mathrm{M}$ & $x$ & $\mathrm{M}$ & 2 \\
\hline 8 & $M$ & $M$ & $M$ & $x$ & $M$ & $M$ & $\mathrm{M}$ & - & $\mathrm{M}$ & $M$ & $\mathrm{M}$ & $\mathrm{M}$ & 10 \\
\hline 9 & $X$ & $X$ & $X$ & $X$ & $M$ & $x$ & $\mathrm{M}$ & $x$ & - & $\mathrm{M}$ & $x$ & $\mathrm{M}$ & 4 \\
\hline 10 & $x$ & $x$ & $x$ & $X$ & $x$ & $x$ & $x$ & $x$ & $x$ & - & $x$ & $\mathrm{M}$ & 1 \\
\hline 11 & $\mathrm{M}$ & $\mathrm{M}$ & $\mathrm{M}$ & $X$ & $\mathrm{M}$ & $\mathrm{M}$ & $\mathrm{M}$ & $x$ & $\mathrm{M}$ & $\mathrm{M}$ & - & $\mathrm{M}$ & 9 \\
\hline 12 & $x$ & $x$ & $x$ & $x$ & $x$ & $x$ & $x$ & $x$ & $x$ & $x$ & $x$ & - & 0 \\
\hline $\begin{array}{l}\text { Number } \\
\text { of Losses }\end{array}$ & 6 & 4 & 3 & 0 & 8 & 5 & 9 & 1 & 7 & 10 & 2 & 11 & - \\
\hline
\end{tabular}

Table 4. Final ranking of criteria according to Copeland method.

\begin{tabular}{|c|c|c|c|c|}
\hline Component & Number of Losses & Number of wins & Wins-losses & Rank \\
\hline Environmental control & 6 & 5 & -1 & 7 \\
\hline Entrance control & 4 & 7 & 3 & 5 \\
\hline Examine the qualifications and credentials of individuals & 3 & 8 & 5 & 4 \\
\hline Physical protection systems & 0 & 11 & 11 & 1 \\
\hline Risk management & 8 & 3 & -5 & 9 \\
\hline Emergency Communications Management & 5 & 6 & 1 & 6 \\
\hline Connections & 9 & 2 & -7 & 10 \\
\hline Security personnel & 1 & 10 & 9 & 2 \\
\hline Training (modeling and simulation) & 7 & 4 & -3 & 8 \\
\hline Protection against toxic substances & 10 & 1 & -9 & 11 \\
\hline The structure of the sport venue & 2 & 9 & 7 & 3 \\
\hline Cultural practices & 11 & 0 & -11 & 12 \\
\hline
\end{tabular}


vote in this pairwise comparison, or the votes are equal, we will be coded it as X. M stands for the row over the column, and X indicates the column over the row. Each pairwise comparison is also examined separately. The last column of Table 3 is the number of wins for each criterion. Also, the final row of the same table shows the number of losses for each criterion. The score that Copeland gives to each option is calculated by subtracting the number of losses from the number of wins; the ranking of options is as Table 4.

The results of table 4 show that physical protection systems are the most important factor in securing sports complexes, followed by security personnel, sports facility structure, qualification and accreditation, entrance control, emergency management, environmental control, Education, risk management, communication, protection against toxic substances and cultural practices.

\section{Discussion}

The objective of this study was to identify and priority of factors affecting sport security in Iran sport venue.

According to the results of this study, physical protection systems are the most important factor in securing sports complexes. It revealed the dimensions of the out-of-view air vents and the warning system, the installation of digital cameras in and out of the sport with the ability to rotate, move and zoom in, continuous control of all sports areas including areas External protection, security and playground security personnel and 24-hour surveillance of the playground by cameras are of paramount importance. This result is consistent with the research of Hemmati Nejad et al. (2016). Hemati Nejad et al. (2016) have conducted research to identify the main factors affecting the security of Iranian football stadiums and prioritize them using a hierarchical analysis method. The results of their research have shown that four factors are infrastructure, physical protection of the stadium, planning, and management of the match, as well as personnel and staff as the most important factors affecting the security of the stadiums. Therefore, installing advanced systems and new cameras in sport venues will reduce the rate of damage due to the lack of physical protection systems used in the security of sports complexes.

It also demonstrates that security personnel is the second factor in securing sports complexes. It determined that the dimensions of the presence of all security personnel in training and planning programs, the provision of security personnel from accredited and qualified organizations, the physical security personnel should be selected from the fulltime staff and supervised by the security chief, and It is important to check the records of all security personnel. This result is consistent with those of Kargar et al. (2017) and Hemmatinejad et al. (2016). Hemmatinejad et al (2016) have shown that the staff is one of the factors affecting the security of stadiums. Therefore, it seems that security forces training should be continuous and require training before training, especially in sensitive matches, in order to increase the security of sports complexes by employing experienced and skilled human resources.

In this study, it has been determined that the structure of the sport venue is one of the factors in securing sports complexes. It has been determined that the geographical location of the sports site is adequate, the number of sports entrance and exit points sufficient for emergencies, the suitability of corridors and access paths, the suitability of corridors and access paths, the availability of dedicated parking in the sports complex and parking facilities. Sufficient capacity is important. This result is in line with those of Kargar et al. (2017). Kargar et al. (2017) have conducted a study to present a model of factors affecting the security of Iranian sporting events. The findings of their research show that the structure of sport facilities is one of the factors affecting the security of sport facilities. As a result, it seems that it is of great importance to consider how to build and equip sports places such as the use of safe and standard facilities, as well as the proper design of sport places. For instance, designing a parking with appropriate capacity based on the number of spectators, is important for the overall structure of the sport places, according to the safety standards of the sports complexes.

In this study, it was found out that reviewing the qualifications and accreditation of individuals is another factor in ensuring the security of sports complexes. It is identified the dimensions of the background check of all vendors, employees, volunteers, and practitioners, issuing a photo ID for all personnel, and issuing new and different ID cards to important tournament personnel. This result is in line with the research of Naderiyan et al. (2013) and Hall (2006). In their research, Hall (2006) showed that reviewing and issuing staff credentials are important factors in the security of sport facilities. Therefore, it is important to employ specialized, experienced and committed people in sports complexes. On the other hand, it is important to identify and control the people who move to sports complexes, sports 
complexes because of their large population of places are vital when it comes to accidents. And the attention and control of people attending sports complexes is important.

In this study, it was found out that the control of the entrances is another factor in securing sports complexes. This reveals the dimensions of the desks outside the front doors and their use for inspecting bags, ensuring a hologram on tickets, inspecting vehicles and all pedestrians on arrival, registration, and exit of vehicles. It is important to use the ID card for drivers and to open all the entries simultaneously. This result is in line with the research of Naderiyan et al. (2013) and Hall (2006). As Hall (2006) has shown in her research, access control is an important factor in the security of college sport venues. Therefore, it is important to put security at the entrance to the sports complexes and determine the entrance routes to the sport venues and to check on those who enter the sports complexes. Multiple pathways to the entrance and increased security at the entrances to the stadiums provide better control so that there are no security issues.

The study found that emergency management is another factor in ensuring the safety of sports complexes. This identified the dimensions of creating, maintaining and practicing emergency evacuation, developing a detailed plan for responding to unexpected events, developing a medical emergency plan, and designating locations for important early medical treatment and transportation. This result was in line with those of Kargar et al. (2017) and Rahimi et al. (2002). As Shah Mansouri and Mozafari (2006) have shown in their research, the most important factor in creating a crisis is mismanagement of potential risks.

In this study, environmental control is identified as another factor in ensuring the safety of sports complexes. It was found that the dimensions of providing a safe environment for the indoor sports grounds, assigning guards to protect vulnerable systems, inspecting and dropping trash, and not installing trash bins underneath buildings and platforms are important. This result is consistent with the research by Hemmati Nejad et al. (2016) and Hall (2006). As Hall (2006) has shown in her research, environmental control factors of the stadium, access control, staff accreditation, physical protection system, risk management, emergency management, return procedures, Communications and interactions, security personnel, training, modeling and simulation, and ultimately countering toxic and chemical substances have been identified as eleven key factors in the security of college sport venues in the United
States. Therefore, checking the environment inside the sports complex and controlling the environment using cameras installed in different locations of the sports complex and controlling all parts is important and is recognized as an important factor in preventing potential hazards.

The study determined that training involves modeling and simulation as another factor in ensuring the safety of sports complexes. It was identified the basic training aspects of how to communicate with guests, solve their problems and basic security practices, teach population control techniques and how to handle them, perform annual evacuation simulations, training security officers and police on how to deal with the bomb threat and to train all staff and volunteers on security alerts and evacuation procedures are important. This finding is in line with those of Naderiyan et al. (2013), Hall et al. (2008) and Hall (2010). As Hall (2010) has discussed in her research the importance of training individuals and staff and their role in the safety and security of sporting events. According to Hall, one of the key components of protecting important infrastructures such as stadiums and sport facilities is the welltrained staff. Therefore, it seems that training of staff, managers, referees, athletes, and spectators of sporting events can be important and will be provided with proper training and how to deal with possible incidents of security in sports complexes. Training of volunteer forces in sporting events should also be considered. Each of these individuals has specific duties in securing the stadium so that they can receive the necessary training in the field.

The study found that risk management is another factor in securing sports complexes. It has identified the dimensions of developing and managing ongoing risk management plans, training of risk management to all staff twice a year, completing risk management programs with the help of specialist forces and holding monthly sport event management meetings with an emphasis on risk management, they are important. This finding is in line with those of Khabiri et al. (2010), Taylor \& Toohey (2011) and Shahmansouri \& Mozafari (2006). In their research, Shahmansouri and Mozafari (2006) have studied the causes of sports crises from the viewpoint of spectators, athletes, coaches, referees and sports reporters. The results indicate that from the viewpoint of the subjects the most important factor in causing the crisis is mismanagement of the possible risks. In their research, Taylor \& Toohey (2011) have shown that the processes and ways to ensure the safety and security of this event are strongly based on the philosophy of risk management. Therefore, 
when dealing with potential risks, it is important to manage potential risks with experienced managers. In addition, there is a need for people with expertise in risk management in sports to manage well when potential risks arise.

In this study, communication was identified as one of the factors in securing sports complexes. It was found that the dimensions of establishing internal communication paths for immediate contact, the presence of large speakers for controlling and guiding the population and determining the hierarchy (decision-making) are important. This result is in line with the research of Hemmati Nejad et al. (2016). So that Hemmatinejad et al. (2016) have shown that effective communication is one of the factors affecting the security of stadiums. Communicating between different groups or the entire sports complex is going to be a very difficult and complicated task. A sports complex manager needs to play a role in defining the communication system and building the communication network on a larger scale. The use of appropriate communication systems among the internal factors of sports complexes with the proper hierarchy as well as the establishment of appropriate communication channels with the people using the sports complexes are important factors in the development and security of sports complexes.

This paper proposed that protection against toxins is another factor in ensuring the safety of sports complexes. It determined that the dimensions of protection against toxic substances should be a part of emergency response programs. Control of the scene by the director of the emergency department of weapons of mass destruction, removal of chemicals with danger potential from the sport site, and special attention to chemicals and gas cylinders that are stored in sport facilities and can be used as a part of an explosive device, is important. This result is in line with the research of Naderiyan et al. (2013) and Hall (2006). In their research, Hall (2006) has shown that one of the effective factors in the security of sports complexes is protection against toxic and chemical substances. As a result, it is important to control and keep away the used toxins from public in sports complexes, as well as to control the collection of toxins in the sports complexes.

Finally, the study found that cultural practices are another factor in securing sports complexes. It found that the dimensions of the distribution of booklets and brochures related to security among customers, information on inspection guidelines and identification of prohibited items, information on sentences and penalties for offenses at the sports site and the creation of billboards were identified. Moreover, security alert boards are important. This result is in line with those of Kargar et al. (2017). In their research, Kargar et al. (2017) have shown that according to the findings of the study, factors affecting the security of sporting events can be divided into five areas of cultural practices, infrastructure, technology, media and propaganda, human resources. Therefore, culture and culture are one of the most important issues in securing sports complexes that can be effective. The norms and values of individuals constitute the most important asset that neglect and abandonment can cause to various crises to cultivate how to use sports complexes using brochures and billboards and to induce desired by installing appropriate boards in the complex and training can improve the security of sports complexes.

\section{Management Implications}

Managers of sports complexes are advised to prepare a checklist before holding sporting events using the factors obtained in this research and to take the necessary measures to control the checklist. Also, due to the limited training of sports staff, it seems necessary that emergency responses to potential events should be trained and facilities should be up to date and the staff of sports complexes have continuous and continuous training exercises.

\section{Conclusions}

In this study, it was found that a variety of factors play a role in the security of sports venues and attention to all these factors obtained for the proper use of sports complexes should be considered. Attention to these factors in all stage of pre-construction, construction and operation of sports facilities should be considered so that in the future we can see safe sports events in these sports complexes. 
Abdolmaleki, H., Mirzazadeh, Z. S., \& Ghahfarokhhi, E. A. (2018). Identify and prioritise factors affecting sports consumer behaviour in Iran. International Journal of Sport Management and Marketing, 18(1-2), 42-62.

Alidostghahfarrokhi, E., \& Ahmadi, A. (2012). The Relationship between Service Quality and Satisfaction of Spectators in Host Stadiums of AFC Championship League. Journal of Sport Management, 4(14), 31 47. doi:10.22059/jsm.2012.28903

Anderson, A., Dixon, M. A., Oshiro, K. F., Wicker, P., Cunningham, G. B., \& Heere, B. (2019). Managerial perceptions of factors affecting the design and delivery of sport for health programs for refugee populations. Sport Management Review, 22(1), 80-95.

Baena-González, R., García-Tascón, M., Chavarría-Ortíz, C., MartínezMartín, I., \& Gallardo, A. M. (2020). Opinion of handball players, trainers and referees using the handball/futsal goalpost anti-tip system" Tutigool" for a safe game: 2019 Four Nations International Handball Junior Tournament. Journal of Physical Education and Sport, 20(4), 1695-1705.

Chen, C.-b., \& Klein, C. M. (1997). An efficient approach to solving fuzzy MADM problems. Fuzzy sets and systems, 88(1), 51-67.

Costa, C. A. (2005). The status and future of sport management: A Delphi study. Journal of Sport Management, 19(2), 117-142.

Cunningham III, G. M. (2007). Security management capabilities in intercollegiate athletic departments. (PhD), University of Southern Mississippi, Mississippi, USA.

Dalkey, N., Brown, B., \& Cochran, S. (1970). The delphi method, IV: Effect of percentile feedback and feed-in of relevant facts. Retrieved from

Del Campo, V., \& Sánchez, P. (2016). Analysis and assessment of the security of the school sport facilities and equipments in the city of Merida (Extremadura). RETOS-Neuvas Tendencias en Educacion Fisica, Deporte y Recreacion(29), 66-71.

Delavar, A.A.A.M.R.A.M. (2008). Sychometric Characteristics of Feeling Security Scale (Tfss) for Tehran Population. Daneshvar Raftar, 25(28), 11.

Delgado, Á. A., \& Gómez, G. E. A. (2018). Manifestations of violence in the football stadium: The case of Granada Football Club. Cultura, Ciencia y Deporte, 1(1), 231-242.

Espinal-Ruiz, D., Medina-Vásquez, J., \& Da Cunha-Bastos, F. (2019). Theories, tensions and convergence of sports development. Cultura, Ciencia y Deporte, 14(42), 203-212.

García-Tascón, M., Guerrero, A. M. G., Luengo, D. B., Martínez-López, Á J., \& González, I. M. (2014). Analysis of security compliance of sport equipment in public management by the municipal sports institute of Seville. Cultura, Ciencia y Deporte, 9(26), 129-138.

Giulianotti, R., \& Klauser, F. (2010). Security governance and sport mega-events: Toward an interdisciplinary research agenda. Journal of Sport and Social Issues, 34(1), 49-61.

Giulianotti, R., \& Klauser, F. (2011). Introduction: Security and surveillance at sport mega events. Urban Studies, 48(15), 3157-3168.

Gordon, K. O., Czekanski, W. A., \& DeMeo, J. A. (2016). Assessing the influence of sport security operations on the guest experience: Using the Delphi method to understand practitioner perspectives. Journal of Sport Safety and Security, 1(1), 2.

Hall, S. (2006). Effective security management of university sport venues. The Sport Journal, 9(4).

Hall, S., Ward, R., Cunningham, T., \& Marciani, L. (2008). Developing a new curriculum in sport security management. Journal of Homeland Security and Emergency Management, 5(1).

Hall, S. A. (2010). An examination of British sport security strategies, legislation, and risk management practices. The Sport Journal, 13(2).

Hall, S. A., Thomas Cieslak, I., Marciani, L., Cooper, W., \& McGee, J. A. (2010). Protective security measures for major sport events: Proposing a baseline standard. Journal of Emergency Management, 8(1), 47-55.

Harati, S., Ashraf Ganjouei, F., Amirtash, A., Nikaeen, Z. (2019). Investigating the Physical Security Dimensions Affecting Volleyball Stadiums Security. Journal of System Management, 5(1), 19.

Hematinezhad, M., Taylor, T., Gholizadeh, M. H., \& Faraji, R. (2016). Prioritizing Factors Affecting the Security of Iranian Football Stadiums
Using Analytical Hierarchy Process. Journal of Sport Management, 8(1) 69-85. doi:10.22059/jsm.2016.58249

Hemmatinezhad, M., Gholizadeh, M. H., Taylor, T., \& Faraji, R. (2016). The Role Of Football Games' Planning And Management On Stadiums' Security. Sport Management and Development, 4(2), 1-14.

Hsu, T., \& Yang, T. (2000). Application of fuzzy analytic hierarchy process in the selection of advertising media. Journal of Management and Systems, 7(1), 19-39.

Hussler, C., Muller, P., \& Rondé, P. (2011). Is diversity in Delphi panelist groups useful? Evidence from a French forecasting exercise on the future of nuclear energy. Technological Forecasting and Social Change, 78(9), 1642-1653.

Ishikawa, A., Amagasa, M., Shiga, T., Tomizawa, G., Tatsuta, R., \& Mieno, H. (1993). The max-min Delphi method and fuzzy Delphi method via fuzzy integration. Fuzzy sets and systems, 55(3), 241-253.

Kargar, G.-A., Ghafouri, F., Mohammadi Moghaddam, Y., \& Moradi Siasar, G.-R. (2017). Presenting a Model of Factors Affecting Security of Iranian Sport Events. Scientific Journal Management System, 8(4), 157-190.

Kashtidar, M., Gholizadeh, B., Okhravi, A. H., \& Abdolmaleki, H. (2017) Identify Assess Service Quality and Performance of Women's Health Clubs in Mashhad Using Combined Fuzzy AHP, QFD \&amp; BSC Method. Sport Management Studies, 9(45), 191-212. doi:10.22089/ smrj.2017.3708.1726

Khabiri, M., Sajadi, S. N., Doosti, M., \& Mohamadian, A. (2010). The Viewpoints of Managers of Football Stadiums on Risk Management in Iran Football Stadiums. Journal of Sport Management, 2(6), 67-149.

Li, D.-F. (2010). A ratio ranking method of triangular intuitionistic fuzzy numbers and its application to MADM problems. Computers \& Mathematics with Applications, 60(6), 1557-1570.

Maciá, M. J., Gallardo, A. M., Sánchez, J., \& García-Tascón, M. (2020) Análisis de la seguridad del equipamiento deportivo en ESO. Apunts. Educación física y deportes, 4(142), 67-75

Majidi, C., Kashef, S. M., Ahadi, B., \& Rasoolazar, G. (2016). The Factors Related to Beautification and joyfulness of university sport places on dorm student's tendency in physical activity. Applied Research in Sport Management, 4(3), 29-39.

Martos-Garcia, D., Devís-Devís, J., \& Sparkes, A. C. (2009). Sport and physical activity in a high security Spanish prison: An ethnographic study of multiple meanings. Sport, Education and Society, 14(1), 77-96.

Maslow, A. H. (1942). The dynamics of psychological security-insecurity. Character \& Personality; A Quarterly for Psychodiagnostic \& Allied Studies.

Menaker, B. E., McGranahan, D. A., \& Sheptak Jr, R. D. (2019). Game day alters crime pattern in the vicinity of sport venues in Cleveland, $\mathrm{OH}$. Journal of Sport Safety and Security, 4(1), 1.

Naderiyan, M., Poorsoltanzarandi, H., \& Rohani, E. (2013). Recognizing Security Indicators and Standards of Sport Facilities. Journal of Sport Management, 5(3), 21-36. doi:10.22059/jsm.2013.35707

Nobakht, F., Ehsani, M., Koozehchian, H., \& Amiri, M. (2015). Effective Success Factors of Small and Medium Enterprise in Sports in Iran. Strategic Studies On Youth and Sports, 28(28), 25-.

Okoli, C., \& Pawlowski, S. D. (2004). The Delphi method as a research tool: an example, design considerations and applications. Information \& management, $42(1), 15-29$

Poursaeed, F. (2008). Human Security in the Constitution of the Islamic Republic of Iran. Strategic Studies Quarterly, 11(41), 545-571.

Pradisathaporn, S., Kaviya, S., Fujii, Y., \& Yupapin, P. P. (2011). An intelligent and multipurpose digital ticket using ad hoc network. Procedia Engineering, 8, 296-300.

Shahmansouri, E. A., \& Mozafari, S. A. A. (2006). The Causes Of Accession In Sport Crisis And The Ways For Preventing Them In Software, Hardware, Liveware And Mass Media Arenas. Research On Sport Science, -(12), 19.

Taylor, T., \& Toohey, K. (2005). Impacts of terrorism-related safety and security measures at a major sport event. Event Management, 9(4), 199-209. 
Taylor, T., \& Toohey, K. (2011). Ensuring safety at Australian sport event precincts: Creating securitised, sanitised and stifling spaces? Urban Studies, 48(15), 3259-3275.

Voorhees, E. (2018). Mitigating Risk: A Delphi Study Identifying Competencies in Sport and Event Security Management. A Dissertation Submitted to the Graduate School,the College of Science and Technology and the Department of Human Capital Developmentat, The University of Southern Mississippi.

Zarei, M. R., Seyed Mohammad Javad. Abdolmaleki, Hossein (2019). A structural model for investigating the role of relationship marketing and brand equity in the development of the business performance of private sport clubs. International Sports Studies, 41(1), 13.

Zavadskas, E. K., Turskis, Z., \& Kildiene, S. (2014). State of art surveys of overviews on MCDM/MADM methods. Technological and economic development of economy, 20(1), 165-179.

Zhang, W. (2004). Handover decision using fuzzy MADM in heterogeneous networks. Paper presented at the 2004 IEEE Wireless Communications and Networking Conference (IEEE Cat. No. 04TH8733) 